\title{
BIOINFORMATION
}

Discovery at the interface of physical and biological sciences

\section{Homology modeling and molecular dynamics simulation study of $\beta$ carbonic anhydrase of Ascaris lumbricoides}

\author{
Mahima Yadav \& Shikha Khandelwal* \\ Amity Institute of Biotechnology, Amity University Haryana, Gurgaon-122413, India; Shikha Khandelwal - Email: \\ writein.shikha@gmail.com; *Corresponding author
}

Received July 12, 2019; Accepted August 12, 2019; Published September 9, 2019

DOI: $10.6026 / 97320630015572$

\begin{abstract}
:
Ascaris lumbricoides is the prevalent parasite causing ascariasis by infecting the human alimentary tract. This is common in the jejunum of small intestine. Therefore, it is of interest to describe the target protein $\beta$ Carbonic Anhydrase involved in Ascariasis. Carbonic anhydrase (CAs, the metallo enzymes) is encoded by six evolutionary divergent gene families $\alpha, \beta, \gamma, \delta$, $\zeta$, and $\eta$, which contain zinc ion in their catalytic active site. $\beta$-CA is found in plants, algae, fungi, bacteria, protozoans, arthropods, and nematodes and completely absent in vertebrate genomes. The absence of $\beta$-CA protein in vertebrate makes the enzyme an important target for inhibitory studies against helminthic infection. The sequence to function related information and 3D structure data for $\beta$-CA of Ascaris lumbricoides is not available. Hence, we modeled the 3D structure (using PRIME) for the molecular dynamics and simulation studies (using the Desmond of Schrödinger software) and interaction analysis (using STRING database). The $\beta$-CA protein found to be interacting with carbonic anhydrase protein family along with T27A3, alh13, mtp18, T22F3, gcy29 proteins. These results provide insights for the understanding of the functional and biological roles played by $\beta$ CA. Hence, this data is useful for the design of drugs for Ascariasis.
\end{abstract}

Keywords: Ascariasis, carbonic anhydrase, structure analysis, homology modeling, Schrodinger software, molecular dynamics.

\section{Background:}

Carbonic anhydrases (CAs) have been recently identified as potential targets for novel anti-infective drugs. CA's are encoded by six evolutionary divergent gene families $\alpha, \beta, \gamma, \delta, \zeta$, and $\eta$ CAs. All members of these gene families are metallo enzymes containing zinc ion in their catalytic active site [1, 2]. $\alpha$-CAs are the most studied family including 13 catalytically active members in mammals: cytosolic enzymes (CA I, CA II, CA III, CA VII, and CA XIII), membrane-bound (CA IV, CA IX, CA XII, CA XIV, and CA $\mathrm{XV}$ ), mitochondrial CAs (VA and CA VB), and secreted CA (VI). Certain $\zeta$ - and $\gamma$-CAs contain cadmium (II), iron (II) or cobalt (II) as alternative metal ion cofactors. $\beta$-CAs are only found in plants, algae, fungi, bacteria, protozoans, arthropods, and nematodes [3]. The $\beta$-CA genes are completely absent in vertebrate genomes and hence they are considered as potential targets for novel antihelminthic diseases [4].

Ascariasis is a disease caused by the parasitic roundworm Ascaris lumbricoides. In more than $85 \%$ of cases, infections have no symptoms, especially if they are small in numbers. Ascariasis is endemic disease, mainly found in tropical and temperate regions of the world, where there is sufficient moisture and in areas which have poverty, ignorance and low standard of hygiene and 


\section{BIOINFORMATION \\ Discovery at the interface of physieal and biological Sceiencess}

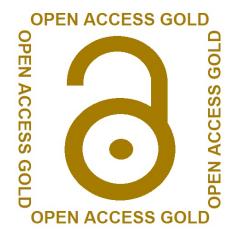

sanitation [5].The clinically approved sulfonamide acetazolamide is the only inhibitor tested on Ascaris lumbricoides $\beta$-CA protein, with an inhibition constant of $84.1 \mathrm{nM}$ [2]. But its inability to penetrate the nematode was found to be a major problem. Therefore, various studies have been carried out to improve the penetration efficacy of $\beta$-CA inhibitors through biological membranes and cuticles of worms. Therefore to better understand the mechanism of interaction of this protein with drug, there is a need to understand the three dimensional structure and interaction part of this protein. In this study, we modeled the 3D structure of $A$. lumbricoides $\beta-C A$ (AlBCA) and also analyzed the different physio chemical and functional properties which would help the researcher to do more advance studies related to function and role of $\beta$ carbonic anhydrase as a target protein for Ascaris lumbricoides.

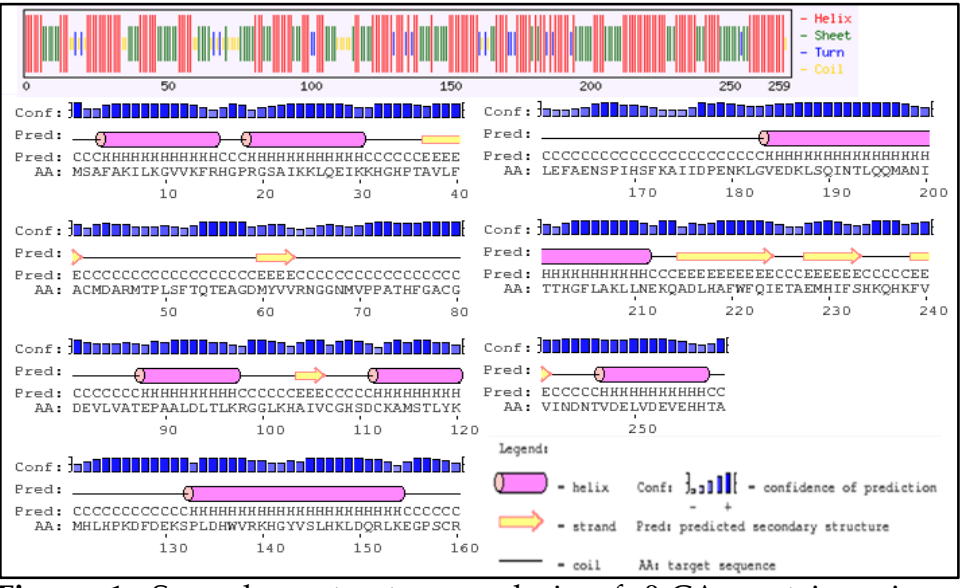

Figure 1: Secondary structure analysis of $\beta$-CA protein using SOPMA.

\section{Methodology:}

Retrieval of $\beta$-CA protein sequence

Protein sequence of the beta carbonic anhydrase of $A$. lumbricoides was retrieved in FASTA format from the UniProt KB/TrEMBL, with accession no: A0A0M3IN45 and 259 amino acid length [6].

\section{Prediction of physico-chemical properties}

The various physical and chemical parameters such as amino acids composition, molecular weight, theoretical isoelectric point, total number of negative and positive charged residues, extinction coefficient, instability index, aliphatic index and GRAVY were calculated using Expasy's ProtParam server [7].
Functional characterization and prediction of secondary structure The motifs or conserved pattern can be identified with the help of Prosite database, Interproscan and SMART database [8]. Secondary structure was predicted using SOPMA tool in Expasy defining the helix, turns and sheet of protein sequence [9].

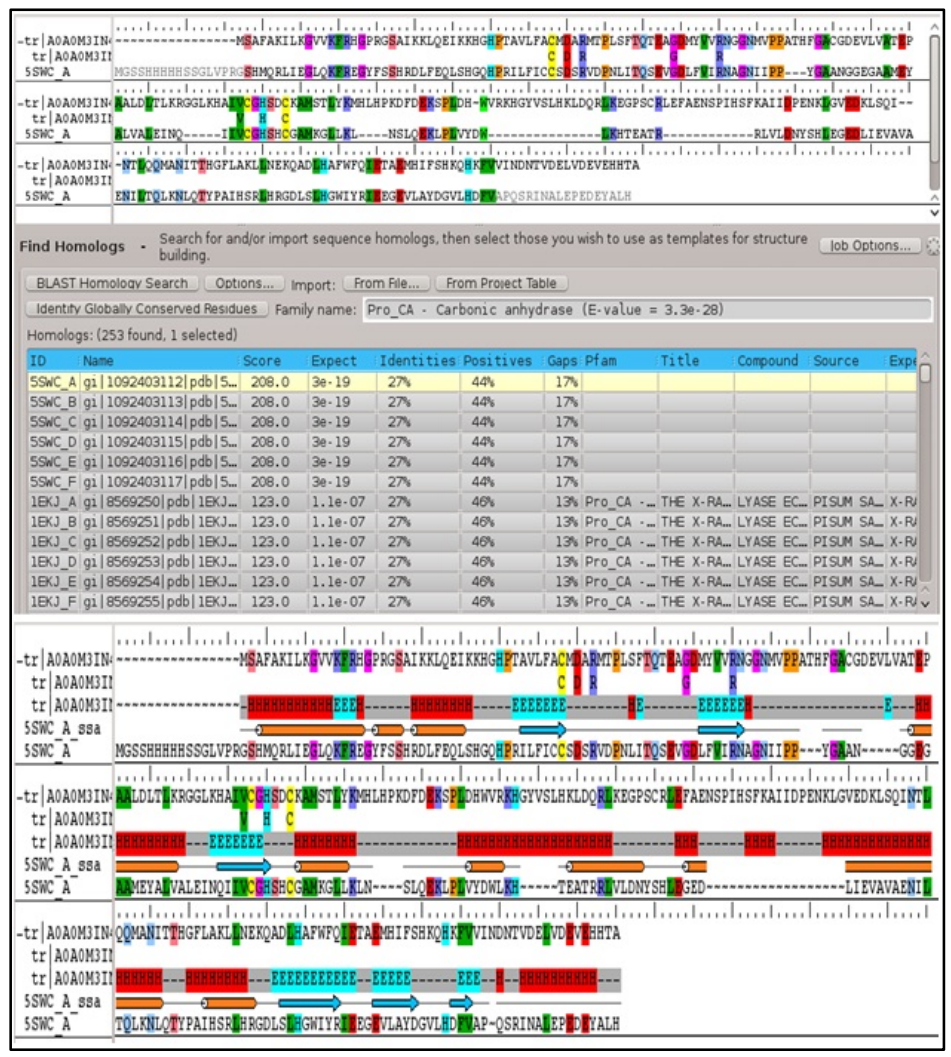

Figure 2: (a) Alignment between target ( $\beta$-CA) and template (Synechocystis sp. (5SWC A)); (b) Alignment showing H for helix; E for strand; and - for loop.

\section{D Homology modelling and validation}

The structure of $\beta$-CA protein of A. lumbricoides is not available in PDB. Therefore, the sequence of $\beta$-CA was downloaded from UniprotKB (ID: A0A0M3IN45). The suitable template for homology modeling was identified on PDB using the BLAST P program [10]. With the help of identified template protein, the 3D model of $\beta$-CAwas built using Prime in Schrödinger Suite 2019-2 [11, 12]. The target $(\beta-C A)$ and template sequences were aligned using the Clustal $W$ method in Prime, followed by 
manual adjustment to avoid big gaps.The overall stability of the protein was assessed using Ramachandran plot [13].

Molecular dynamic (MD) simulations

The modelled 3D structure of $\beta$-CA was further optimized using MD simulations. The MD simulations were performed using Desmond Molecular Dynamics module [11, 12] of Schrodinger. Energy of the prepared systems was minimized for 2000 iterations using steepest descent method. The default parameters in Desmond were applied for system equilibration. The 100 ns (nano seconds) MD simulations were then carried out with the equilibrated systems at a temperature of $300 \mathrm{~K}$ and at a constant pressure of 1atm, under the NPT (normal pressure and normal temperature) ensemble with a time step of $2 \mathrm{fs}$ (femto seconds).

\section{Prediction of binding site}

Modelled protein structure was used to identify the active binding sites using sitemap program of Schrödinger software.

\section{Functional analysis and protein-protein interaction study:}

STRING v10.0 server [14] was used to find out the $\beta$-CA proteinprotein interactions of $A$. lumbricoides with other closely related proteins and functional protein association network was generated.

\section{Result \& Discussion:}

The protein sequence of $\beta-C A$, retrieved from UNIPROT (ID: A0A0M3IN45) is 259 amino acids in length. The physiochemical properties of $\beta$-CA were calculated using ProtParam (Table 1). The amino acid composition indicated the maximum percentage of Leu residues i.e $9.3 \%$ and followed by Ala and Lys with $8.5 \%$ and $8.9 \%$ respectively. Highest percentage of leucine residue in $\beta$-CA might be correlated with presence of leucine switch motif. PI value of 7.33 defines the slightly alkaline behaviour of the protein and instability index 44.09 which is higher than 40 defined its unstable nature. This instability was expected due to presence of certain dipeptides, which is different in unstable proteins as compared to stable ones. Higher aliphatic index (81.74) suggested that protein is thermostable and the lower value of GRAVY (-0.328) indicated the possibility of better interaction with water. Extinction coefficient at $280 \mathrm{~nm}$ is $15470 \mathrm{M}^{-1} \mathrm{~cm}^{-1}$ with respect to concentrations of Cys, Trp and Tyr. This coefficient helps in the quantitative study of proteinprotein and protein-ligand interactions in solution.

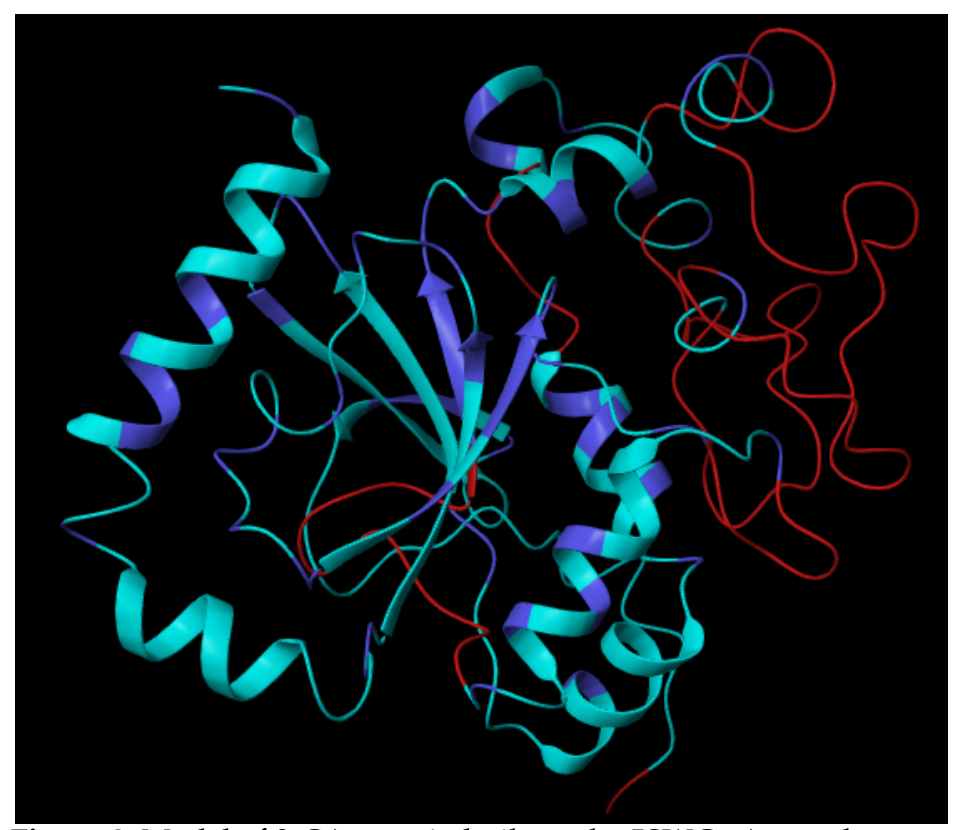

Figure 3: Model of $\beta$-CA protein built on the 5SWC _A template.

The motifs or conserved pattern was identified in the sequence. The domain Pro_CA was found in the sequence from 30 to 233 in length out of 259 amino acid sequence with E value 8.98e-22.Interproscan result showed protein family membership or homologous superfamily is carbonic anhydrase (IPR001765) and detailed signature matches with PF00484(Pro CA) and SM00947 (Pro CA 2) of carbonic anhydrase. Secondary structure prediction was done by using SOPMA. The result showed that the percentage of alpha helix was more than the sheet and turn (Figure 1). The percentage of alpha helix was found to be $40.15 \%$, beta sheets to be $6.44 \%$ and beta turn was to be $8.9 \%$. No disordered protein binding sites were identified in this protein and this $40.15 \% \quad \alpha$-helix makes this protein stable for homology modelling.

\begin{tabular}{|c|c|c|c|c|c|c|c|c|}
\hline Length & $\begin{array}{l}\text { Molecular } \\
\text { weight }\end{array}$ & $\begin{array}{l}\text { Theoretical } \\
\text { pI }\end{array}$ & $\begin{array}{l}\text { Aliphatic } \\
\text { index }\end{array}$ & $\begin{array}{l}\text { Grand } \\
\text { average of } \\
\text { hydropathicity } \\
\text { (GRAVY) }\end{array}$ & $\begin{array}{l}\text { Instability } \\
\text { index }\end{array}$ & $\begin{array}{c}\text { Extinction } \\
\text { coefficients }\end{array}$ & $\begin{array}{l}\text { negatively } \\
\text { charged } \\
\text { residues } \\
(\text { Asp +Glu) }\end{array}$ & 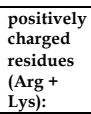 \\
\hline 259 & 29029.4 & 7.33 & 81.74 & $\begin{array}{l}-0.328 \\
\end{array}$ & 44.09 & 15470 & 31 & 31 \\
\hline
\end{tabular}




\section{BIOINFORMATION}

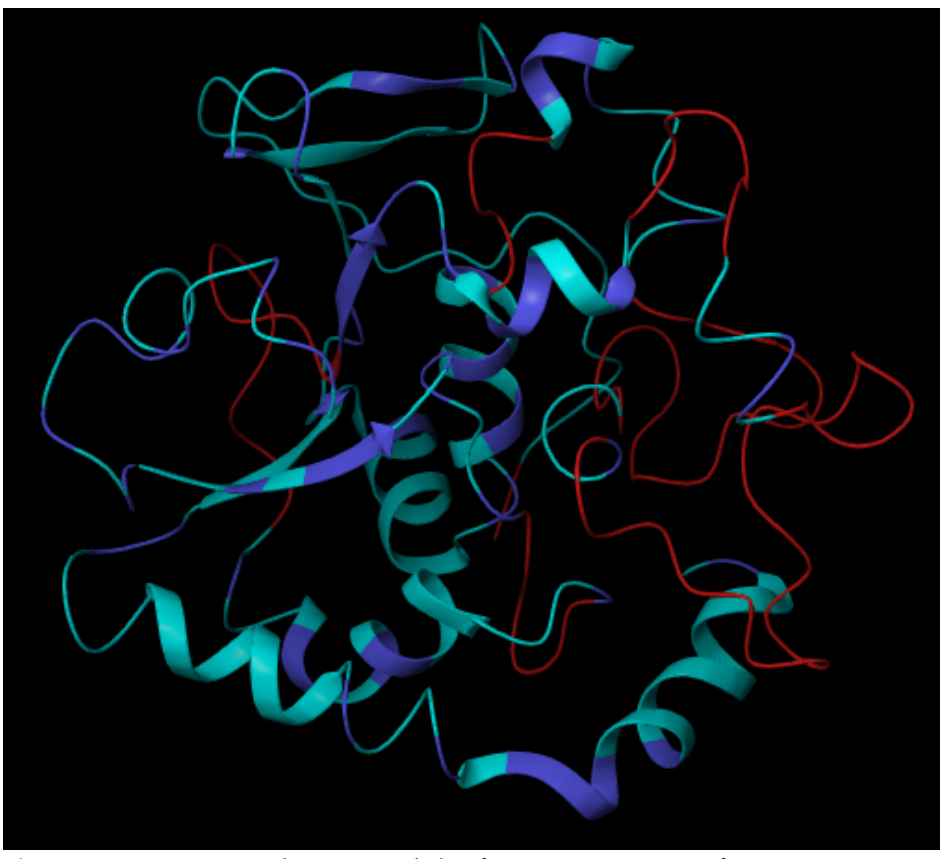

Figure 4: Optimized 3D Model of $\beta$-CA protein after 100 ns MD simulations

Since, there were no resolved 3D structures available for the $\beta$-CA protein of $A$. lumbricoides in PDB. In literature, it was reported that for homology modelling, sequence identity between target and template proteins should be $25 \%$ and more [15]. So, in this study, an attempt was made to model the 3D structure through homology modelling using BLAST P against known protein structures deposited in PDB. The crystal structure of Synechocystis sp. (5SWC A) was selected with a $27.98 \%$ sequence similarity for the target sequence. The sequence alignment between the template (5SWCA) and the target was shown in Figure 2 (a) \& (b). Homology modelling was done using the PRIME of Schrodinger Suite 2019-2. The homology model so obtained was further refined by Protein Prep (Protein preparation) wizard in Schrodinger software. This refinement mainly involves stabilization of the protein by hydrogen bond addition, structure optimization and energy minimization. Figure 3showed the modelled structure of $\beta$-CA and the ribbon diagram of super imposed structures of the template and target, respectively. The build $3 \mathrm{D}$ structure of $\beta$-CAobtained by homology modelling was further refined and optimized using MD simulation. In MD simulations, RMSD (Root Mean Square Deviation) serves as a measure to determine the stability of $\beta$-CA structure based on its deviation from the initial structure. The optimized 3D model was shown in Figure 4. The RMSD values of $\beta$-CA residues in the entire MD simulation trajectory were shown in Figure 5.

Table 2: Binding sites of $\beta$-CA protein
\begin{tabular}{|l|l|l|l|l|l|}
\hline S. No & Title & Site score & Size & D. score & Volume \\
\hline 1 & Sitemap_1_site_1 & 1.068 & 187 & 1.054 & 340.5 \\
\hline 2 & Sitemap_1_site_2 & 1.016 & 177 & 1.004 & 337.8 \\
\hline 3 & Sitemap_1_site_3 & 0.940 & 176 & 0.967 & 441.0 \\
\hline 4 & Sitemap_1_site_4 & 0.818 & 76 & 0.820 & 205.1 \\
\hline 5 & Sitemap_1_site_5 & 0.759 & 49 & 0.747 & 83 \\
\hline
\end{tabular}

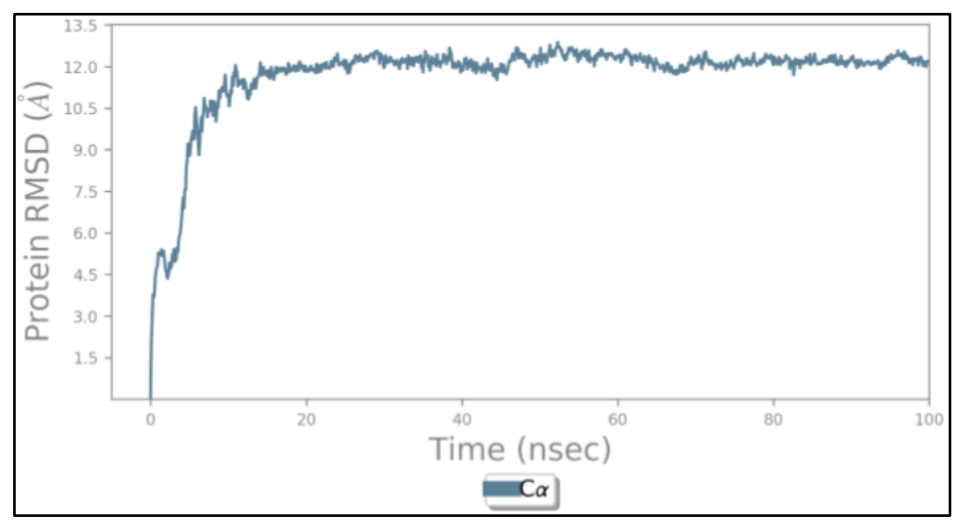

Figure 5: RMSD graph of the $\beta$-CA protein

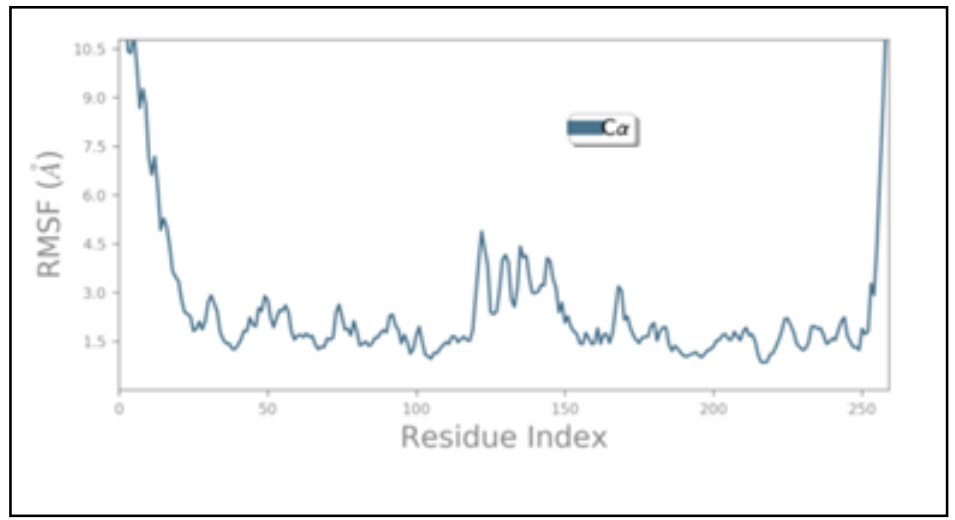

Figure 6: RMSF graph of the $\beta$-CA protein 


\section{BIOINFORMATION \\ Discovery at the interface of physical and hiological Scciences}

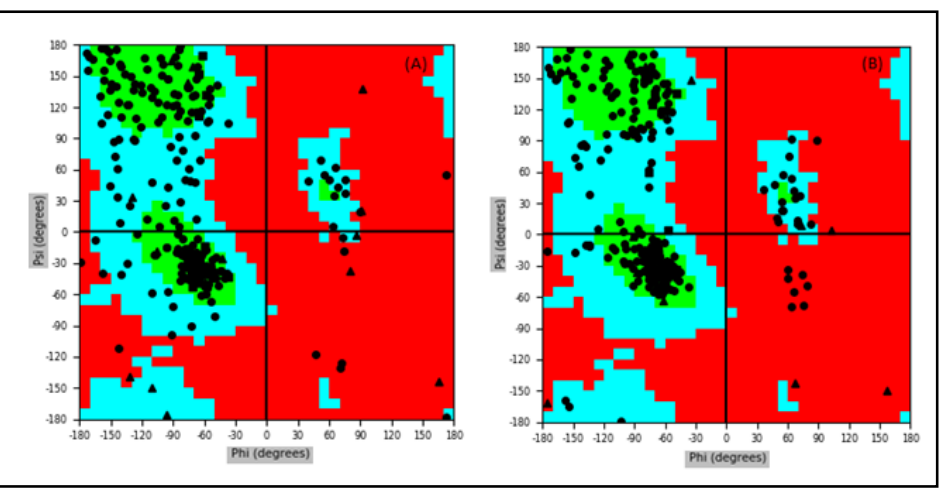

Figure 7: Ramachandran plot of Modelled $\beta$-CA protein at 0 ns (A) and 100ns (B), respectively

The $\beta$-CA structure showed deviations up to $10.5 \AA$ and then gave a stable trajectory beyond that. The $3 \mathrm{D}$ structure of $\beta$-CA reached to a stable state after $9 \mathrm{sec}$. Figure 6 shows RMSF (root mean-square fluctuations) of $\beta$-CA structure generated during the MD simulation and these fluctuations were calculated to characterize the mobility of individual residues. On this plot, peaks indicate areas of the protein that fluctuate the most during the simulation. Typically the tails $(\mathrm{N}$ - and $\mathrm{C}$ terminal) fluctuate more than any other part of the protein. Secondary structure elements like alpha helices and beta strands are usually more rigid than the unstructured part of the protein, and thus fluctuate less than the loop regions. The fluctuations reported were within $4.5 \AA$ indicating that the amino acid fluctuations were in acceptable range. The stereo chemical quality of the 3D model was validated by Ramachandran plot. Figure 7 showed that around $97.29 \%$ residues were present in the allowed regions $(92.66 \%$ in the favoured region and $4.6 \%$ residues in the allowed regions) and only $2.7 \%$ residues were present in the outlier region indicating that the quality of the model was good. Binding sites prediction was also done using sitemap program (Table 2). The result showed five binding sites and best binding site was identified with a Dscore of 1.068. Functional analysis revealed ten potential interacting partners of $\beta$-CA protein in the protein interaction network as resolved by STRING analysis. The $\beta$-CA protein has interaction with Carbonic anhydrase protein family along with T27A3, alh13, mtp18, T22F3, gcy29 protein (Figure 8).

ISSN 0973-2063 (online) 0973-8894 (print)

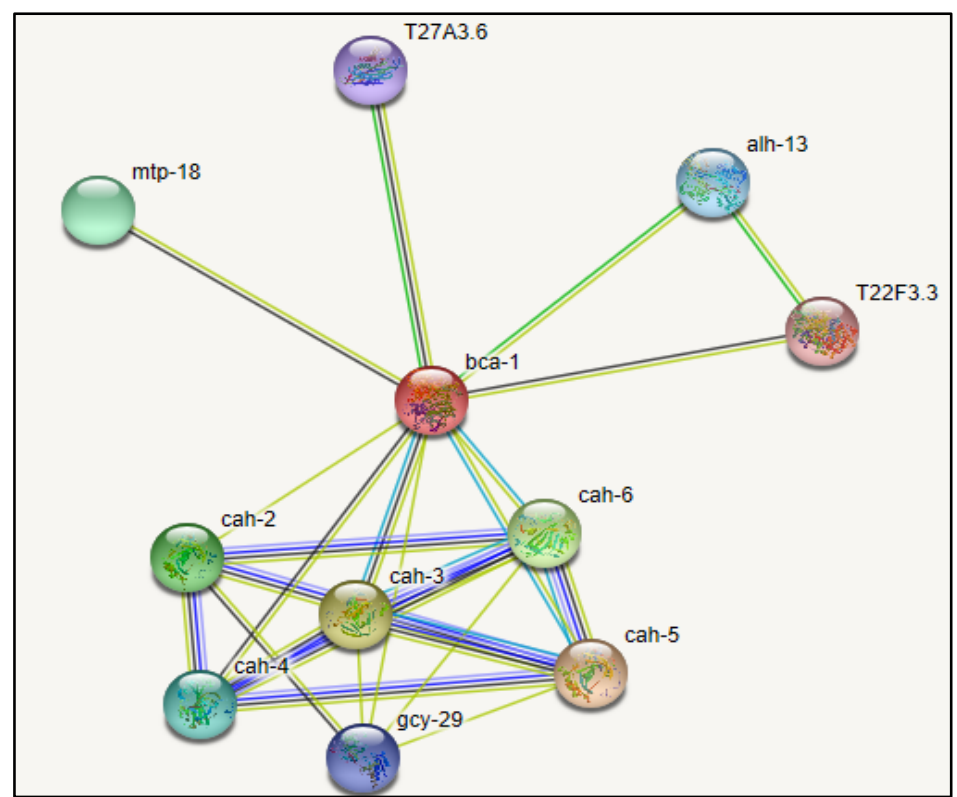

Figure 8: Protein-protein interaction map for the $\beta$-CA of $A$. lumbricoides.

\section{Conclusion:}

The 3D structure of the $\beta$-CA protein was modelled using PRIME, further optimized by 100 ns molecular dynamic simulations and validated by Ramachandran plot. Detailed data for the structure and function of $\beta-\mathrm{CA}$ is not available till date. Moreover, the absence of $\beta$-CAs in vertebrates makes this enzyme as a potential target for various helminthic diseases. The modelled 3D structure of $\beta$-CAs is of use for anti-parasitic drug designing using known potential binding sites of protein. This in silico study will help in designing new broad-spectrum and preferably single dose $\beta$-CA inhibitors, against Ascaris lumbricoides $\beta$-CA.

\section{Acknowledgement:}

The authors are thankful to AIB, Amity University, Haryana for providing Schrodinger software to carry out the current study. We would also like to thank Mr. Vinod Devaraji who helped with the application part of Schrodinger software. The open access publication charge for this article is sponsored by Biomedical Informatics (P) Ltd, India and it is acknowledged.

\section{Conflict of interest:}

Authors declared no conflict of interest. This study received no funding or sponsorship of any form. 


\section{BIOINFORMATION \\ Discovery at the interface of physical and biological sciences}

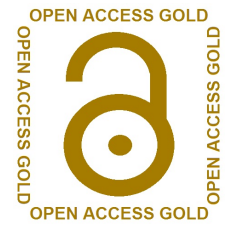

\section{References:}

[1] Syrjanen Let al. BMC Biochem. 2010 11:28. [PMID: 20659325]

[2] Zolfaghari Emameh R et al. Parasit Vectors. 2015 8:479. [PMID: 26385556]

[3] Rowlett RS. Biochem Biophys Acta. 2010 1804:362. [PMID: 19679201]

[4] Capasso C \& Supuran CT. J Enzyme Inhib Med Chem. 2015 30:325. [PMID: 24766661]

[5] Shah J \& Shahidullah A. Case Rep Gastroenterol. 2018 12:224. [PMID: 29928187]

[6] Bairoch A \& Apweiler R. Nucleic Acids Res. 2000 28: 45. [PMID:10592178]

[7] Gasteiger E. In: John M. Walker (ed.) The Proteomics Protocols Handbook, Humana Press. 2005571.

[8] Falquet L et al. Nucl Acids Res. 2002 30: 235. [PMID: 11752303]

[9] Geourjon C \& Deleage G. Comput Appl Biosci. 1995 11:681. [PMID: 8808585]

[10] Marsden RL, Orengo CA. Methods Mol. Biol. 2008 426:3. [PMID: 18542854]

[11] Jacobson MP et al. J. Mol. Biol. 2002 320: 597.

[12] Jacobson MP et al. Proteins: Structure, Function and Bioinformatics 2004 55:351.

[13] Ramachandran GN et al. J Mol Biol. 1963 7:95. [PMID: 13990617]

[14] Szklarczyk et al. Nucleic Acids Res. 2015 43:D447. [PMID: 25352553]

[15] Yang AS \& Honig B. J. Mol. Biol. 2000 301:691. [PMID: 10966778]

Edited by $P$ Kangueane

Citation: Yadav \& Khandelwal, Bioinformation 15(8): 572-578 (2019)

License statement: This is an Open Access article which permits unrestricted use, distribution, and reproduction in any medium, provided the original work is properly credited. This is distributed under the terms of the Creative Commons Attribution License 


\section{BIOINFORMATION}

Discovery at the interface of physical and biological sciences
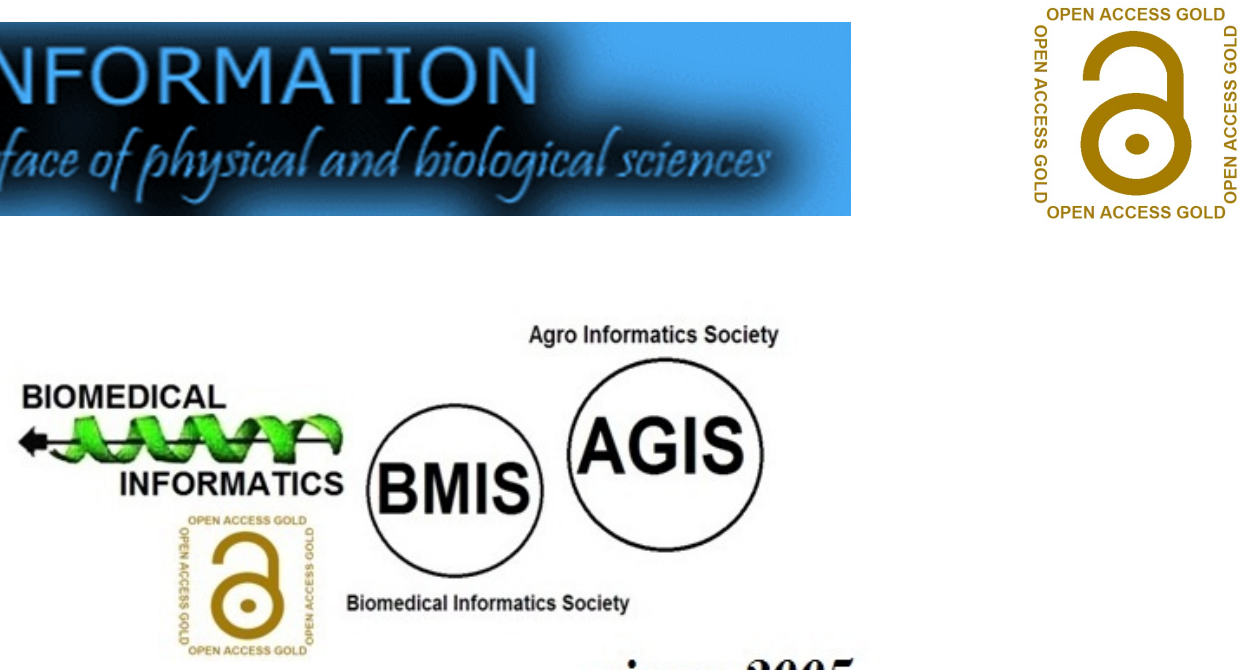

since 2005

\section{BIOINFORMATION}

Discovery at the interface of physical and biological sciences

\section{indexed in}

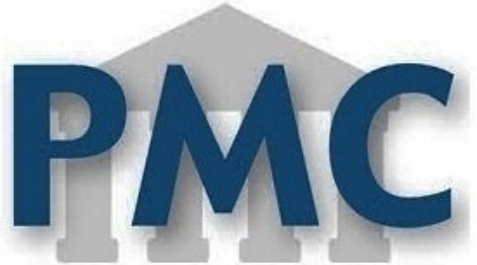

PublMed

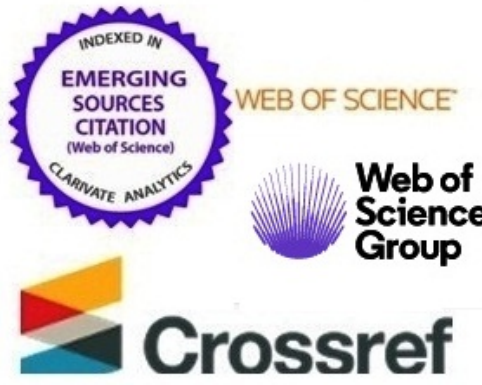

EBSCO

Web of

Science

roup

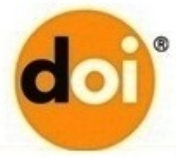

ResearchGate
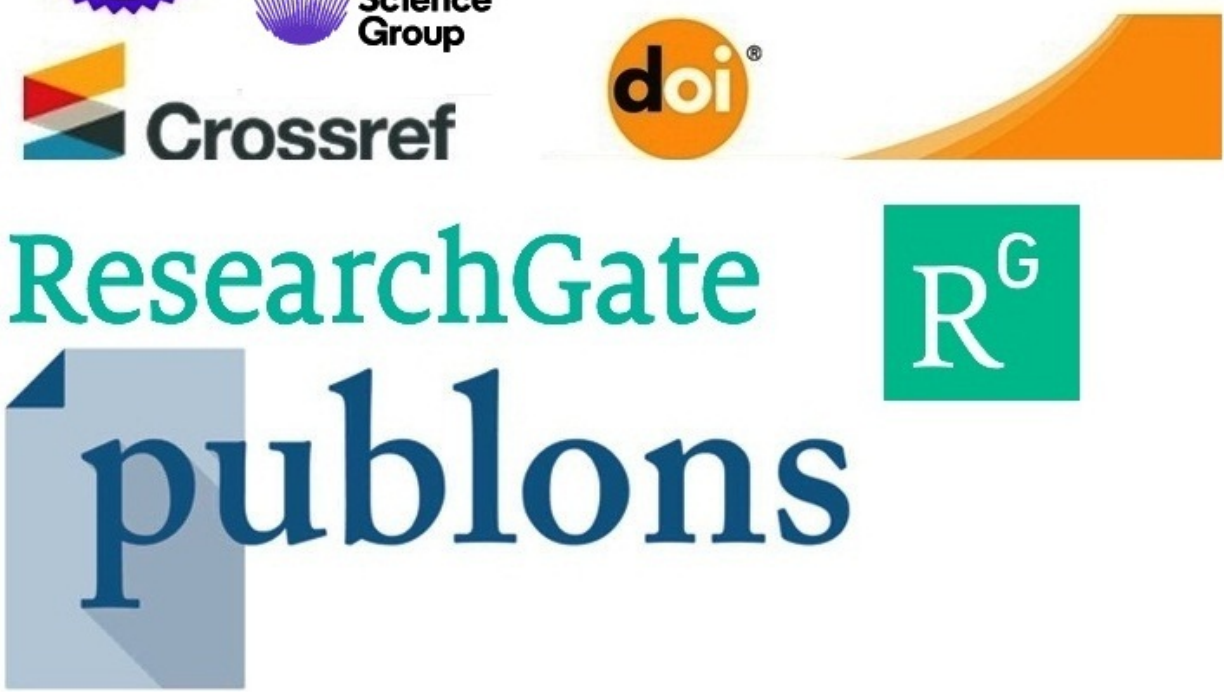